\title{
Completion of administrative procedures by the developer (technical customer)
}

\author{
Tatiana Kuzmina*, Polina Bolshakova, Diana Zueva \\ Moscow State University of Civil Engineering, 129337, Moscow, Russia
}

\begin{abstract}
This article analyzes the measures to improve the business climate in the construction sector (roadmap), implemented in Russia in recent years. The indicators of Russia in the international Doing Business rating are analyzed; an improvement in Russia's position in the field of favorable conditions for doing business, despite the difficult economic situation in the country is revealed. The main indicators of the effectiveness of optimizing the completion of procedures were the introduction of an exhaustive list of procedures with a description, the elimination of redundant (duplicate) procedures, a reduction in the duration of the procedure, and the introduction of digital technologies during the completion of procedures. Despite the reforms carried out in Russia, depending on the region, there are a number of problems of a different nature when going through the procedures at the stages of pre-design and project preparation, which entail an increase in time and financial costs. Because of this, it becomes necessary to develop additional measures to optimize procedures related to getting building permission.
\end{abstract}

\section{Introduction}

In recent years, the investment attractiveness of Russia has declined. This is due to the introduction of economic sanctions, which in turn affects the conditions of economic cooperation between Russia and foreign partners in the trade and investment-technological areas $[1,2,3,4]$.

At the same time, the country's indicators in the World Bank's Doing Business rating improve every year [5].

This dynamics is associated with the approval of the Action Plan "Improving the business climate in the building sector" by the Government of the Russian Federation on August 16, 2012 and with its subsequent implementation [6].

The purpose of developing the roadmap action plan was to create a favorable business climate in the Russian Federation by reducing excessive administrative barriers, reducing the number of procedures, time, cost and labor costs for their completion at the stage of urban planning documentation preparation and to commissioning [7]. To achieve these goals, it was envisaged to develop normative and legal acts to improve the legal regulation of urban planning activities [8].

*Corresponding author: KuzminaTK@mgsu.ru 


\section{Methods}

Town-Planning Code of the Russian Federation endured the introduction of a number of amendments, which in turn led to the adoption of a number of resolutions of the government of the Russian Federation, one of which was the Resolution of the Government of the Russian Federation No. 403 "On an exhaustive list of procedures in the field of housebuilding". It was adopted on April 30, 2014 [9]. This Resolution contains an exhaustive register of descriptions of procedures for the construction of various facilities. Before the adoption of this list, there were more than 220 administrative procedures, but the development of this provision was aimed at optimizing the completion of administrative procedures, at identifying and canceling redundant and (or) duplicate procedures specified in the list. As a result, there were 139 administrative procedures in the approved register. Today, the number of procedures is reduced to 90 positions.

Many procedures were reduced. They include the conclusion of an agreement for housing down with hot water, conducting an examination and laboratory tests of building materials at the request of the State Construction Supervision and Inspection Service, and for obtaining approval for design documentation from the sanitary inspection service, etc.

Based on the fact that the Resolution provides an exhaustive list of procedures for each specific object, according to its characteristics and construction conditions, an individual set of necessary procedures is selected.

Excessive administrative barriers reduced the profitability of the constructed object, its cost increased due to the costs of developers to create a construction product.

Today, the investor, developer (technical customer), contractors have a clear idea of the completeness and composition of the submitted documents, the timing and result of receiving public services $[10,11,12,13]$. These changes helped to reduce corruption risks.

As a result, over 8 years, Russia has risen in the World Bank's Doing Business ranking in the Ease of Doing Business from 120 to 28 position, and in the Getting a Building Permission from 178 to 26 , which indicates the right path to improvement of business climate in construction (Figures 1,2).

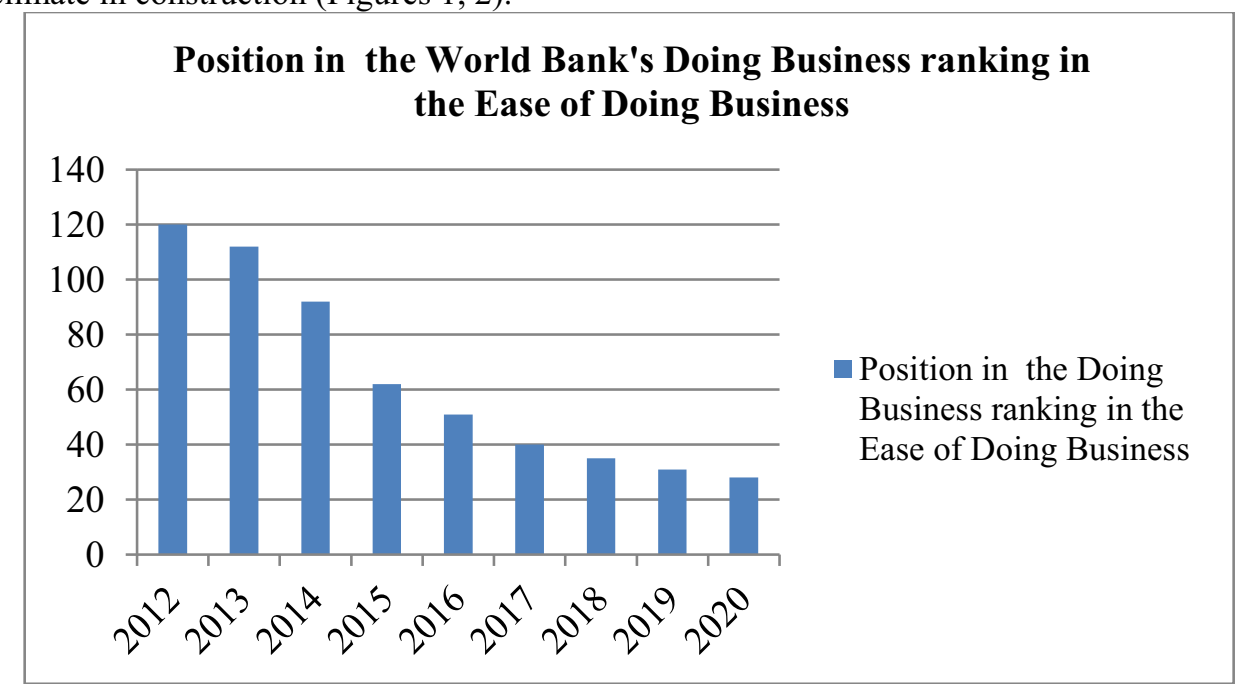

Fig. 1.Indices in the World Bank's Doing Business ranking in the Ease of Doing Business (20122020) 


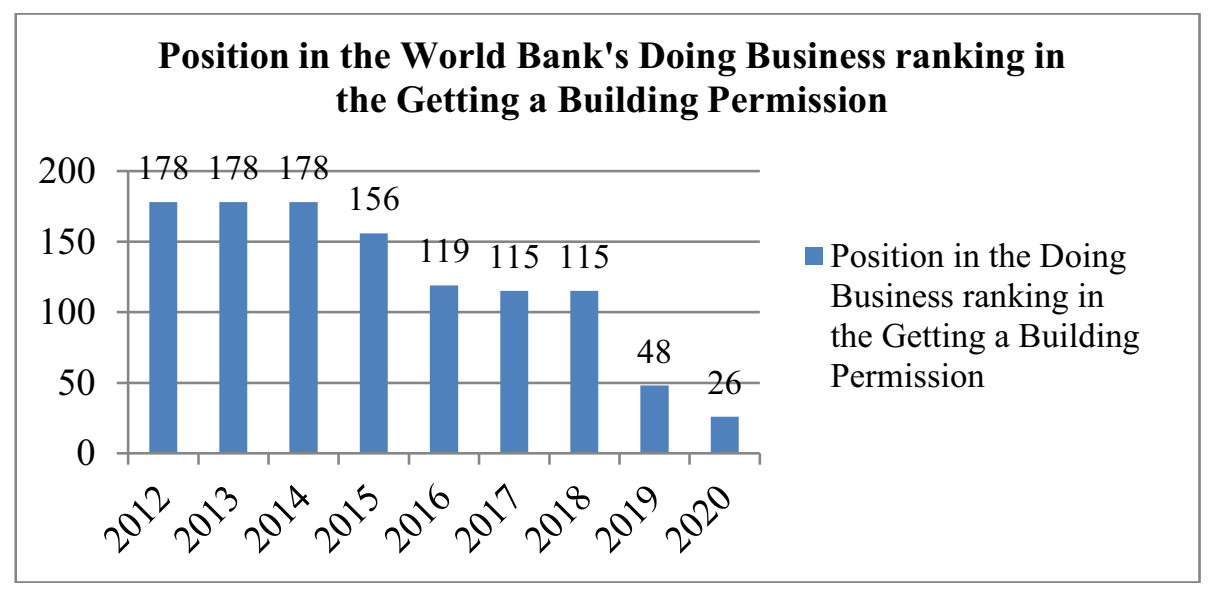

Fig.2. Indices in the World Bank's Doing Business ranking in the Getting a Building Permission (2012-2020)

The World Bank's Doing Business rating is based on a survey of developers in 189 countries of the world and, as a result, plays a great role in determining the most profitable countries in terms of investments attracting.

The World Bank assesses the rating in the direction of "Getting a Building Permission" only in large cities of different countries. In Russia, Moscow and St. Petersburg and other large cities are considered. At the same time, the procedures of a reference object, a warehouse with a height of two floors and a total area of 1.3 thousand square meters, are considered. The warehouse is intended for storage of non-hazardous goods. The assessment of the number of procedures, the time of their completion and the cost is carried out; the quality index of construction control is also taken into account (Table 1).

Before the reforms, to get a permission for the construction of a facility with these characteristics, it was necessary to go through many approvals during several years. To date, the number of procedures and the time required to complete them has been more than halved. For example, in Moscow the number of procedures decreased from 35 to 14, and in St. Petersburg to 11. The financial costs of administrative procedures also decreased: in Moscow from 3.9 to 1.2 , in St. Petersburg to 0.9 . According to the parameter "Quality Control Index in Construction" Moscow and St. Petersburg scored 14 out of 15 possible points. The same point was assigned to Singapore, which ranks fifth in the direction of "Getting a Building Permission". Such a score in Moscow and St. Petersburg is due to the high level of control over the quality and safety of facilities due to the system of regulation in construction that developed during the Soviet years. In terms of other parameters, Russia can be compared with the United States and Great Britain.

Table 1. The World Bank's Doing Business ranking in the Getting a Building Permission (2012-2020)

\begin{tabular}{|l|c|c|c|c|c|c|c|c|c|}
\hline \multicolumn{1}{|c|}{ Parameter } & 2012 & 2013 & 2014 & 2015 & 2016 & 2017 & 2018 & 2019 & 2020 \\
\hline $\begin{array}{l}\text { The number of procedures } \\
\text { required to get a building } \\
\text { permission (Moscow) }\end{array}$ & 35 & 27 & 23 & 15 & 15 & 15 & 15 & 14 & 14 \\
\hline $\begin{array}{l}\text { The number of procedures } \\
\text { required to get a building } \\
\text { permission (Saint- } \\
\text { Petersburg) }\end{array}$ & - & - & 15 & 15 & 15 & 12 & 12 & 11 & 11 \\
\hline
\end{tabular}




\begin{tabular}{|l|l|l|l|l|l|l|l|l|l|}
\hline $\begin{array}{l}\text { The totality of the time to } \\
\text { complete all stages of the } \\
\text { procedures for getting a } \\
\text { building permission } \\
\text { (Moscow), day }\end{array}$ & 438 & 287 & 271 & 221 & 207.5 & 202.5 & 202.5 & 164.5 & 160 \\
\hline $\begin{array}{l}\text { The totality of the time to } \\
\text { complete all stages of the } \\
\text { procedures for getting a } \\
\text { building permission (Saint- } \\
\text { Petersburg), day }\end{array}$ & - & - & 252 & 252 & 252 & 203 & 203 & 179 & 175 \\
\hline $\begin{array}{l}\text { Costs required to get a } \\
\text { building permission } \\
\text { (Moscow), \% of the value of } \\
\text { the object }\end{array}$ & 3.9 & 2.8 & 2 & 1.8 & 1.7 & 1.5 & 1.4 & 1.3 & 1.2 \\
\hline $\begin{array}{l}\text { Costs required to get a } \\
\text { building permission (Saint- } \\
\text { Petersburg), \% of the value } \\
\text { of the object }\end{array}$ & - & - & 1.5 & 1.4 & 1.3 & 1.2 & 1.1 & 1 & 0.9 \\
\hline $\begin{array}{l}\text { Quality control index in } \\
\text { construction (completion of } \\
\text { the procedures required to } \\
\text { get a building permission) }\end{array}$ & - & - & - & 13 & 13 & 13 & 13 & 14 & 14 \\
\hline
\end{tabular}

The transparency of administrative procedures was significantly influenced by the possibility of transferring public services in the construction sector to electronic form. The authorities of Moscow, the Moscow region and St. Petersburg have been the most successful in this field. Construction complexes reduce the processing time for applications from developers, partially automated control of the timing and progress of the provision of public services is carried out. Data on projects are brought together in a single electronic database of projects, which allows one to quickly access information $[14,15,16]$.

Studying the best practices and summarizing the results, when implementing the action plan "Improving the legal regulation of urban planning activities and improving the business climate in the construction sector" according to the parameter "Getting a building permission", identified the main problems that arose before developers and technical customers [6]:

- long terms for passing all the procedures for getting a building permission;

- high complexity of procedures for getting a building permission;

- low transparency of the processes of issuing permits and decisions made for the developer and technical customer;

- low literacy of developers and technical customers in the use of information technology.

\section{Results and discussions}

Today, in Moscow, 15 government services are provided exclusively in electronic form. One can get remote services for issuing a city development plan for a land plot, for issuing architectural and town planning solutions, a state expert opinion, as well as for issuing a building permission, etc.

Since 2018, it has become possible to receive electronic services of resource supplying organizations, in particular, filing applications for obtaining technical specifications, concluding connection agreements, obtaining technological connection certificates. 
To simplify the collection of initial information about the conditions of the land plot, an information infrastructure has been created. The composition of the city development plan for land has been expanded, including information on the engineering networks located within the boundaries of the land plot and on technical conditions providing for the maximum load at possible connection points.

A section "Guide to services" was created on the portal. It contains information about the procedures and the course of their completion, regulations, legal documents, information about the bodies providing public services.

The creation of a single digital space for all participants in investment and construction activities is one of the priority tasks of the construction industry at the present stage.

The technical customer service is a professional partner for the investor, customer and developer, representing their interests and being a guarantor in ensuring the quality of services performed in the field of research, design and construction of objects.

In such conditions, the technical customer (depending on the completed contract) accompanies the implementation of the project from the collection of initial data on the site where the construction of the facility is planned and to the facility commissioning.

The main problems arising with the use of information modeling in the work of a technical customer are associated with the use of modern project management technologies, the formation of customer requirements and boundary conditions at each stage, ensuring the quality and reliability of information transfer from one construction participant to another at different stages of the project.

When digitization of a number of procedures, time is saved due to the acceleration of the information exchange between all participants in the process. At the same time the developer (technical customer), in addition to the need for full-time visits to the authorities, offices of subordinate and resource supplying organizations, receives services and information through a huge list of electronic resources, in particular: federal and regional portals of state and municipal services, an information system for supporting urban planning activities, a federal state information system for territorial planning, a federal information address system, and a unified register of expert opinions.

In Moscow, Moscow region, St. Petersburg, the process of introducing digital technology is well underway. However, when analyzing the situation in other regions of the country, a different situation emerges. On average in the country, according to the Ministry of Construction of Russia at the end of 2017, only 3\% of services in construction were in electronic form. There is also a number of problems associated with the work of local self-government bodies that violate the terms for the provision of services, request unnecessary documents and approvals when providing services.

Currently, the list of administrative procedures and the order of their completion may differ depending on the region, which leads to the fact that the developer's service prefers to work in regions with known specifics of the relevant procedures [17].

In general, the key administrative procedures in the construction sector can be unified for cities in all regions. However, each city has its own urban planning features that must be regulated at the local level. Most of all, this applies to large cities (megalopolises), because they have a high density of population and buildings and a complex system of engineering communications and urban connections.

In Moscow, the completion of administrative procedures is a more complicated and complex process in comparison with the regions. Moscow has a large number of historically significant buildings and structures, a complex transport and engineering infrastructure. Moscow occupies huge areas, there is the largest number of inhabitants and population density. Such parameters should be taken into account when developing construction standards and measures for its regulation. All this entails a significant increase 
in the number of not only the procedures themselves, but also the institutions with which the developer must interact [18]

Despite the state optimization to reduce the number of procedures and the timing of their completion when getting a building permission from a developer (technical customer), problem situations often arise that lead to deviations from the regulated deadlines [19]. Suchproblemsareasfollows:

- complaints from other participants in the land auction, competition for potentially illegal actions of the seller, considered by the Office of the Federal Antimonopoly Service;

- adjustment of architectural and urban planning solutions (booklet);

- an increase in the time required for obtaining technical specifications for connection to engineering networks;

- provision of technical specifications, developed using inaccurate topographic survey data;

- complaints from other bidders to determine a contractor for potentially illegal actions of the developer (technical customer), considered by the Office of the Federal Antimonopoly Service;

- making corrections to the set of documentation identified when submitting an electronic application for an examination;

- - correction of the reporting documentation of the results of engineering surveys when deficiencies are discovered during state or non-state expertise;

- correction of project documentation (collection of additional initial data) in the event of deficiencies (insufficient initial data) during state or non-state expertise;

- lack of a unified information environment for receiving services in electronic form.

\section{Conclusions}

Despite the optimization carried out by the state to reduce the number of administrative procedures and the timing of their passage at the present time, they take a long time and, until now, entail a financial and temporary problem (for example, obtaining a permission for temporary connection to city utility networks).

It is important to note, that today there is no single digital space for all participants in investment and construction activities.

In such conditions, identifying the features of the implementation and application of BIM technologies in the activities of a technical customer is one of the urgent problems at the present time.

Reducing the time required to complete certain procedures to minimum values leads to a situation of multiple refusals due to the inability to carry out the approval procedure within the time allotted for it. This suggests that it is necessary to optimize the work of the person who makes the decision to issue the procedures. To do this, it is necessary to provide the necessary conditions for decision-makers for objective, competent and accurate work in a limited time.

The above problems indicate the need to continue measures to improve the business climate in the field of construction and to optimize the administrative procedures required to get building permissions.

The following proposals can be formulated as measures for further optimization of procedures:

- the introduction of digital technologies in the regions; 
- completion administrative procedures on the principle of "one window", through the already operating Unified Housing Information System (UHIS);

- transfer of regional procedures to the federal level;

- detailing federal regulation of procedures;

- approval of uniform standards of public services, including uniform request forms.

\section{References}

1. J. Aderhold, V.Yu. Davydov, F. Fedler, H. Klausing, D. Mistele, T. Rotter, O. Semchinova, J. Stemmer and J. Graul, J. Cryst. Growth 222, 701 (2001).

2. P.P. Oleinik, Natural and technical sciences 10, 412-414 (2015).

3. P.P. Oleinik, and T.K. Kuzmina, Technology and organization of construction production 2 18-20 (2013).

4. T.D. Polydi, Property relations in the Russian Federation 2 (149), 89-99 (2014).

5. E.S. Shtranina, and T.K. Kuzmina, Industrial and civil construction in modern conditions 183-184 (2011).

6. A.A.Dynkin, and V.G. Baranovsky, Economy and Foreign Policy. Annual forecast 147 (2015).

7. T.K. Kuzmina Scientific Review 2, 192-195 (2016).

8. A.V. Galyamova, and T.K. Kuzmina, Technology and organization of construction production 2 6-9 (2018).

9. V.P. Grakhov, A.A. Baldina, and S.A. Mokhnachev, Management and economics 16 (343) 2-6 (2014).

10. P.N. Kostrikin, Economy and entrepreneurship 12-1 (77) 527-533 (2016).

11. M.F. Kuzhin, Natural and technical sciences 10 (88) 409-411 (2015).

12. A.A. Lapidus, Technology and organization of construction production, 21 (2013).

13. S.A. Sinenko, and A.M. Slavin, Scientific Review 1 98-103 (2016).

14. P.P. Oleinik, and T.K. Kuzmina, Technology and organization of construction production 2 18-20 (2013).

15. T.K. Kuzmina, S.A. Sinenko, and A.M. Slavin, Industrial and civil construction 6 7175 (2016).

16. T.K. Kuzmina, and S.A. Sinenko, Scientific Review 18 156-159 (2015).

17. T.D. Polydi, and T.K. Baikova, Urban planning 3 (37) 8-10 (2015).

18. O.V. Fokina, and A.N. Korkishko, Don's Engineering Herald 2 (45) 147 (2017).

19. A.A. Lapidus, and N.D. Cherednichenko Scientific Review 21 338-341 (2015).

20. P.V. Bolshakova Science and Business: Ways of Development 1 (79) 9-12 (2018). 